\title{
Small-molecule Crystallography in the Battery Electrolyte Development
}

\author{
Yulia Sevryugina, ${ }^{1}$ Oscar Tutusaus, ${ }^{2}$ Rana Mohtadi ${ }^{2}$ \\ ${ }^{1}$ Texas Christian University, TCU Box 298860, Fort Worth, TX 76132, USA \\ ${ }^{2}$ Toyota Research Institute of North America, 1555 Woodridge Avenue, Ann Arbor, MI 48105, USA
}

Rechargeable $\mathrm{Mg}$ batteries have been proposed as candidates for post lithium-ion batteries due to their higher volumetric capacity, lower cost, and absence of dendrite formation. One of the current challenges in their development is the identification of electrolyte that is noncorrosive and chemically stable to $\mathrm{Mg}$ metal. Here, we will share a structural characterization of a new electrolyte, magnesium monocarborane (MMC), that stands out as the first simple-salt magnesium compound, providing high anodic stability, non-corrosive, and chemically robust.

Dissolving MMC in various glymes (monoglyme (G1 or DME), diglyme (G2), and tetraglyme (G4)) resulted in crystallization of MMC-glyme solvates $\left[\mathrm{Mg}(\mathrm{G} 1)_{3}\right]\left(\mathrm{CB}_{11} \mathrm{H}_{12}\right)_{2} \quad(\mathbf{1})$, $\left[\mathrm{Mg}(\mathrm{G} 2)_{2}\right]\left(\mathrm{CB}_{11} \mathrm{H}_{12}\right)_{2} \cdot(\mathrm{G} 2)$ (2), and $\left[\mathrm{Mg}(\mathrm{G} 4)_{2}\left(\mathrm{H}_{2} \mathrm{O}\right)\right]\left(\mathrm{CB}_{11} \mathrm{H}_{12}\right)_{2}$ (3), respectively. Their X-ray diffraction analysis revealed $\mathrm{Mg}$ solvent-separated ion pairs, indicative of a high level of salt dissociation despite the low solvent polarity. Moreover, in the case of G4 two or more adjacent oxygen atoms at one end of the tetraglyme are not involved in $\mathrm{Mg}$ coordination, perhaps assisting effective salt dissolution through cation-anion asymmetry.

In the solid state structure of $\mathbf{1}$ two carborane half-cages displayed symmetry induced disorder for C- and B-atoms, which was modeled by allowing shared 0.5:05 occupancy for B and C occupying the same position. The crystal structure of $\mathbf{2}$ is an inversion twin and the ratio of the two twin components refined to $0.65: 0.35$. In 3 , one of the side chains of G4 displayed a positional disorder, which was refined with the 0.6:0.4 ratio between two orientations. The final $R 1$ values were $0.0794(\mathrm{w} R 2=0.2222)$ for 4904 reflections $[I>2 \sigma(I)] ; 0.0350(\mathrm{w} R 2=0.0883)$ for 7162 reflections $[I>2 \sigma(I)]$; and $0.0649(\mathrm{w} R 2=0.1670)$ for 1564 reflections $[I>2 \sigma(I)]$ for $\mathbf{1}$, $\mathbf{2}$, and $\mathbf{3}$, respectively. 